\title{
Physical punishment of children: lessons from 20 years of research
}

\author{
Joan Durrant PhD, Ron Ensom MSW RSW
}

See related editorial by Fletcher on page 1339 and at www.cmaj.ca/lookup/doi/10.1503/cmaj.121070

$\mathrm{O}$ ver the past two decades, we have seen an international shift in perspectives concerning the physical punishment of children. In 1990, research showing an association between physical punishment and negative developmental outcomes was starting to accumulate, and the Convention on the Rights of the Child had just been adopted by the General Assembly of the United Nations; however, only four countries had prohibited physical punishment in all settings.

By 2000 , research was proliferating, and the convention had been ratified by 191 of the world's 196 countries, 11 of which had prohibited all physical punishment. Today, research showing the risks associated with physical punishment is robust, the convention has been integrated into the legal and policy frameworks of many nations, and 31 countries have enacted prohibitions against the physical punishment of children. ${ }^{1}$ These three forces - research, the convention and law reform - have altered the landscape of physical punishment.

The growing weight of evidence and the recognition of children's rights have brought us to a historical point. Physicians familiar with the research can now confidently encourage parents to adopt constructive approaches to discipline and can comfortably use their unique influence to guide other aspects of children's healthy development. In doing so, physicians strengthen child well-being and parent-child relationships at the population level. Here, we present an analysis of the research on physical punishment spanning the past two decades to assist physicians in this important role.

\section{The early years: identifying patterns}

As recently as 20 years ago, the physical punishment of children was generally accepted worldwide and was considered an appropriate method of eliciting behavioural compliance that was conceptually distinct from physical abuse. However, this perspective began to change as studies found links between "normative" physical punishment and child aggression, delinquency and spousal assault in later life. Some of these studies involved large representative samples from the United States; ${ }^{2}$ some studies controlled for potential confounders, such as parental stress ${ }^{3}$ and socioeconomic status; ${ }^{4}$ and some studies examined the potential of parental reasoning to moderate the association between physical punishment and child aggression. ${ }^{5}$ Virtually without exception, these studies found that physical punishment was associated with higher levels of aggression against parents, siblings, peers and spouses.

But were physical punishment and childhood aggression statistically associated because more aggressive children elicit higher levels of physical punishment? Although this was a possibility, ${ }^{6}$ research was beginning to show that physical punishment elicits aggression. Early experiments had shown that pain elicits reflexive aggression.? In an early modeling study, ${ }^{8}$ boys in grade one who had watched a one-minute video of a boy being yelled at, shaken and spanked with a paddle for misbehaving showed more aggression while playing with dolls than boys who had watched a one-minute video of nonviolent responses to misbehaviour. In a treatment study, Forgatch showed that a reduction in harsh discipline used by parents of boys at risk for antisocial behaviour was followed by significant reductions in their children's aggression. ${ }^{9}$ These and other findings spurred researchers to identify the
Competing interests: Ron Ensom is part of the national knowledge transfer initiative on physical punishment at the Children's Hospital of Eastern Ontario. No other competing interests were declared.

This article has been peer reviewed.

Correspondence to: Joan Durrant, durrant@cc.umanitoba.ca

CMAJ 2012. DOI:10.1503 /cmaj.101314 
mechanisms linking physical punishment and child aggression.

By the 1990s, it was recognized that the method by which causality is typically shown in scientific studies - the randomized control trial - had limited application for studying the physical punishment of children. Although randomized control trials can be used to study the effect of reducing physical punishment (as in the Forgatch study), they cannot be used to study the effect of imposing such punishment because it would be unethical to assign children to a group receiving painful treatment when research suggests that such pain poses harm not outweighed by potential benefit. The few existing randomized control trials showed that physical punishment was no more effective than other methods in eliciting compliance. In one such study, an average of eight spankings in a single session was needed to elicit compliance, and there was "no support for the necessity of the physical punishment."10

To address the causality question within ethical bounds, researchers designed prospective studies involving children who had equivalent levels of aggression or antisocial behaviour at the beginning of the study. In addition, increasingly sophisticated statistical modeling techniques were applied to correlational studies to aid understanding of the results. These studies changed the way in which physical punishment would be researched over the subsequent decade and redrew the landscape of the debate.

\section{The new millennium: addressing causation and broadening focus}

One of the first large prospective studies (1997, $n=807$ ) controlled for initial levels of child antisocial behaviour and sex, family socioeconomic status and levels of emotional support and cognitive stimulation in the home. ${ }^{11}$ Even with these controls, physical punishment between the ages of six and nine years predicted higher levels of antisocial behaviour two years later. Subsequent prospective studies yielded similar results, whether they controlled for parental age, child age, race and family structure ${ }^{12}$ poverty, child age, emotional support, cognitive stimulation, sex, race and the interactions among these variables $;{ }^{13}$ or other factors. ${ }^{14-17}$ These studies provide the strongest evidence available that physical punishment is a risk factor for child aggression and antisocial behaviour.

A landmark meta-analysis published in $2002^{18}$ showed that of 27 studies on physical punishment and child aggression conducted up to that time (that met the criteria of the meta-analysis), all found a significant positive relation, regardless of the size of the sample, location of study, ages of the children or any other variable. Almost all adequately designed studies conducted since that meta-analysis have found the same relation. ${ }^{19-23}$ In a randomized controlled trial of an intervention designed to reduce difficult child behaviours, ${ }^{24}$ parents in more than 500 families were trained to decrease their use of physical punishment. The significant parallel decline seen in the difficult behaviours of children in the treatment group was largely explained by the parents' reduction in their use of physical punishment. Together, results consistently suggest that physical punishment has a direct causal effect on externalizing behaviour, whether through a reflexive response to pain, modeling or coercive family processes.

By 2000, research on physical punishment had expanded beyond its effect on child aggression. Studies were showing associations between physical punishment and mental health, physical injury, parent-child relationships and family violence in adulthood. One of the first such studies ${ }^{25}$ linked slapping and spanking in childhood with psychiatric disorders in adulthood in a large Canadian sample, and its findings have since been supported by an ever-growing number of studies. Physical punishment is associated with a range of mental health problems in children, youth and adults, including depression, unhappiness, anxiety, feelings of hopelessness, use of drugs and alcohol, and general psychological maladjustment. ${ }^{26-29}$ These relationships may be mediated by disruptions in parent-child attachment resulting from pain inflicted by a caregiver, ${ }^{30,31}$ by increased levels of cortisol $^{32}$ or by chemical disruption of the brain's mechanism for regulating stress. ${ }^{33} \mathrm{Re}$ searchers are also finding that physical punishment is linked to slower cognitive development and adversely affects academic achievement. ${ }^{34}$ These findings come from large longitudinal studies that control for a wide range of potential confounders. ${ }^{35}$ Intriguing results are now emerging from neuroimaging studies, which suggest that physical punishment may reduce the volume of the brain's grey matter in areas associated with performance on the Wechsler Adult Intelligence Scale, third edition (WAIS-III). ${ }^{36}$ In addition, physical punishment can cause alterations in the dopaminergic regions associated with vulnerability to the abuse of drugs and alcohol. ${ }^{37}$

These findings are all consistent with the growing body of literature on the impact of adverse childhood experiences on neurological, cognitive, emotional and social development, as well as physical health. ${ }^{38}$ Although some studies have found no relation between physical punish- 
ment and negative outcomes, ${ }^{35}$ and others have found the relation to be moderated by other factors, ${ }^{12}$ no study has found physical punishment to have a long-term positive effect, and most studies have found negative effects. ${ }^{17}$

Another major change in the landscape was precipitated by research that questioned the traditional punishment-abuse dichotomy. Although research began to accumulate in the 1970s that showed that most physical abuse is physical punishment (in intent, form and effect), studies of child maltreatment have since clarified this finding. For example, the first cycle of the Canadian Incidence Study of Reported Child Abuse and Neglect $^{39}$ (CIS 1998) showed that $75 \%$ of substantiated physical abuse of children occurred during episodes of physical punishment. This finding was replicated in the second cycle of the study (CIS 2003). ${ }^{40}$ Another large Canadian study ${ }^{41}$ found that children who were spanked by their parents were seven times more likely to be severely assaulted by their parents (e.g., punched or kicked) than children who were not spanked. In an American study, ${ }^{42}$ infants in their first year of life who had been spanked by their parents in the previous month were 2.3 times more likely to suffer an injury requiring medical attention than infants who had not been spanked. Studies of the dynamics of child physical abuse have shed light on this process, which involves parents attributing conflict to child willfulness ${ }^{43}$ and/or rejection, ${ }^{44}$ as well as coercive family dynamics ${ }^{9}$ and conditioned emotional responses. ${ }^{45}$

The mounting evidence linking negative longterm outcomes to physical punishment has contributed to a global shift in perceptions of the practice. In Canada, more than 400 organizations have endorsed the Joint Statement on Physical Punishment of Children and Youth. ${ }^{46}$ A subset of these organizations is listed in Appendix 1 (available at www.cmaj.ca/lookup/suppl/doi:10.1503 /cmaj.101314/-/DC1). In other countries, legislative reforms have been instituted to better protect children. ${ }^{47}$ Accompanying these changes has been a growing emphasis on developing models of positive discipline that rely on nonviolent and effective conflict resolution.

\section{The future: promoting nonviolent parenting}

There is considerable evidence that providing support and education to parents can reduce their use of physical punishment and children's externalizing behaviours. Most of the programs that have been evaluated are behaviourally based, with origins in the work of Patterson and col- leagues. ${ }^{48}$ In these programs, parents are taught to observe their children's behaviour, communicate clearly and apply contingent consequences. Meta-analyses of studies evaluating these programs show positive effects on the competence, efficacy and psychological health of the parents, as well as on the behaviour of the children. ${ }^{49,50} \mathrm{~A}$ recent implementation study of a strategy for parenting and family support showed that families in the treatment group had far fewer cases of substantiated child maltreatment, abuse injuries and out-of-home placements. ${ }^{51}$

The consistency of research findings on physical punishment and positive discipline, along with growing support for the aims of the Convention on the Rights of the Child, has had a substantial impact on the views of health care providers. The Canadian Paediatric Society, "strongly discourages [original emphasis] the use of physical punishment on children, including spanking." 52 The American Academy of Pediatrics cautions that "corporal punishment is of limited effectiveness and has potentially deleterious side effects," and "recommends that parents be encouraged and assisted in the development of methods other than spanking for managing undesired behavior." 53

It is now 20 years since Canada ratified the Convention on the Rights of the Child, which calls for the elimination of all forms of violence against children, including physical punishment. The debate has moved beyond discussions of outcomes and causality to those of ethics and human rights. This new context for examining physical punishment has propelled legal, policy and attitudinal changes worldwide. ${ }^{47}$ An increasing number of countries are abolishing the use of physical punishment to better protect children and to shift parents' focus from punishment to guidance and effective discipline. Evidence is emerging that the combination of law reform and public education is more effective than either strategy alone in changing parental attitudes and behaviours. ${ }^{54}$

Physicians have a primary responsibility for translating research and evidence into guidance for parents and children, and they are credible and influential voices for advancing public education and policy concerning population health. For example, physicians can educate parents on child development to reduce angry and punitive responses to normative child behaviours and provide resources on positive discipline. ${ }^{46}$ In addition, physicians may refer parents to public health programs, resource centres, positive parenting programs and other clinical professionals for further support. Furthermore, physicians can engage with other professionals to send clear, unambiguous messages on a population level. 
Examples of such messages are "Spanking hurts more than you think" (Toronto Public Health) and "Never spank!" (Public Health Agency of Canada) ${ }^{55,56}$ Finally, physicians can urge the federal government to remove section 43 from the Criminal Code, which provides legal justification for the use of physical punishment, thereby undermining public education initiatives.

The Joint Statement on Physical Punishment of Children and Youth finds

The evidence is clear and compelling - physical punishment of children and youth plays no useful role in their upbringing and poses only risks to their development. The conclusion is equally compelling — parents should be strongly encouraged to develop alternative and positive approaches to discipline. ${ }^{46}$

Effective discipline rests on clear and ageappropriate expectations, effectively communicated within a trusting relationship and a safe environment. ${ }^{57}$

\section{References}

1. Global initiative to end all corporal punishment of children. Available: www.endcorporalpunishment.org (accessed 2012 Jan. 4)

2. Straus MA. Ordinary violence, child abuse, and wife-beating: What do they have in common? In: Finkelhor D, Gelles R, Hotaling G, et al., editors. The dark side of families: current family violence research. Beverly Hills (CA): Sage; 1983. p. 213-34.

3. Travillion K, Snyder J. The role of maternal discipline and involvement in peer rejection and neglect. J Appl Dev Psychol 1993;14:37-57.

4. Straus MA. Discipline and deviance: physical punishment of children and violence and other crime in adulthood. Soc Probl 1991; 38:133-54.

5. Larzelere RE. Moderate spanking: Model or deterrent of children's aggression in the family? J Fam Violence 1986;1:27-36.

6. Straus MA. Some social antecedents of physical punishment: a linkage theory interpretation. J Marriage Fam 1971;33:658-63.

7. Azrin NH, Hake DF, Hutchinson RR. Elicitation of aggression by a physical blow. J Exp Anal Behav 1965;8:55-7.

8. Fairchild L, Erwin WM. Physical punishment by parent figures as a model of aggressive behavior in children. J Genet Psychol 1977;130:279-84.

9. Forgatch MS. The clinical science vortex: a developing theory of antisocial behaviour. In: Pepler DJ, Rubin KH, editors. The development and treatment of childhood aggression. Hillsdale (NJ): Erlbaum. p. 291-315.

10. Day DE, Roberts M. An analysis of the physical punishment component of a parent training program. J Abnorm Child Psychol 1983;11:141-52.

11. Straus MA, Sugarman DB, Giles-Sims J. Spanking by parents and subsequent antisocial behavior of children. Arch Pediatr Adolesc Med 1997;151:761-7.

12. Gunnoe ML, Mariner CL. Toward a developmental-contextual model of the effects of parental spanking on children's aggression. Arch Pediatr Adolesc Med 1997; 151:768-75.

13. Grogan-Kaylor A. Corporal punishment and the growth trajectory of children's antisocial behavior. Child Maltreat 2005;10:283-92.

14. Mulvaney MK, Mebert CJ. Parental corporal punishment predicts behavior problems in early childhood. J Fam Psychol 2007; 21:389-97.

15. Slade EP, Wissow LS. Spanking in early childhood and later behaviour problems: a prospective study of infants and young toddlers. Pediatrics 2004;113:1321-30.

16. Taylor CA, Manganello JA, Lee SJ, et al. Mothers' spanking of 3 -year-old children and subsequent risk of children's aggressive behavior. Pediatrics 2010;125:e1087-1065.

17. Grogan-Kaylor A. The effect of corporal punishment on antisocial behavior in children. Soc Work Res 2004;28:153-62.

18. Gershoff ET. Corporal punishment by parents and associated child behaviors and experiences: a meta-analytic and theoretical review. Psychol Bull 2002;128:539-79.
19. Aucoin KJ, Frick PJ, Bodin SD. Corporal punishment and child adjustment. J Appl Dev Psychol 2006;27:527-41.

20. Fine SE, Tretacosta CJ, Izard CE, et al. Anger perception, caregivers' use of physical discipline, and aggression in children at risk. Soc Dev 2004;13:213-28.

21. Lansford JE, Chang L, Dodge KA, et al. Physical discipline and children's adjustment: cultural normativeness as a moderator. Child Dev 2005;76:1234-46.

22. Ohene SA, Ireland M, McNeely C, et al. Parental expectations, physical punishment, and violence among adolescents who score positive on a psychosocial screening test in primary care. Pediatrics 2006;117:441-7.

23. Pagani LS, Tremblay RE, Nagin D, et al. Risk factor models for adolescent verbal and physical aggression toward mothers. Int $J$ Behav Dev 2004;28:528-37.

24. Beauchaine TP, Webster-Stratton C, Reid MJ. Mediators, moderators, and predictors of 1-year outcomes among children treated for early-onset conduct problems: a latent growth curve analysis. J Consult Clin Psychol 2005;73:371-88.

25. MacMillan HL, Boyle MH, Wong MYY, et al. Slapping and spanking in childhood and its association with lifetime prevalence of psychiatric disorders in a general population sample. CMAJ 1999;161:805-9.

26. Afifi TO, Brownridge DA, Cox BJ, et al. Physical punishment, childhood abuse and psychiatric disorders. Child Abuse Negl 2006; 30:1093-103.

27. Turner HA, Muller PA. Long-term effects of child corporal punishment on depressive symptoms in young adults: potential moderators and mediators. J Fam Issues 2004;25:761-82.

28. Javo C, Rønning JA, Heyerdahl S, et al. Parenting correlates of child behavior problems in a multiethnic community sample of preschool children in northern Norway. Eur Child Adolesc Psychiatry 2004;13:8-18.

29. Rodriguez CM. Parental discipline and abuse potential affects on child depression, anxiety, and attributions. J Marriage Fam 2003; 65:809-17.

30. Coyl DD, Roggman LA, Newland LA. Stress, maternal depression, and negative mother-infant interactions in relation to infant attachment. Infant Ment Health J 2002;23:145-63.

31. Palmer EJ, Hollin CR. Sociomoral reasoning, perceptions of parenting and self-reported delinquency in adolescents. Appl Cogn Psychol 2001;15:85-100.

32. Bugental DB, Martorell GA, Barraza V. The hormonal costs of subtle forms of infant maltreatment. Horm Behav 2003;43: 237-44.

33. McGowan PO, Sasaki A, D'Alessio AC, et al. Epigenetic regulation of the glucocorticoid receptor in human brain associates with childhood abuse. Nat Neurosci 2009;12:342-8.

34. Straus MA, Paschall MJ. Corporal punishment by mothers and development of children's cognitive ability: a longitudinal study of two nationally representative age cohorts. J Aggress Maltreat Trauma 2000;18:459-83.

35. Bradley RH, Corwyn RF, Burchinal M, et al The home environments of children in the United States Part II: relations with behavioral development through age thirteen. Child Dev 2001;72: 1868-86

36. Tomoda A, Suzuki H, Rabi K, et al. Reduced prefrontal cortical gray matter volume in young adults exposed to harsh corporal punishment. Neuroimage 2009;47:T66-71.

37. Sheu Y-S, Polcan A, Anderson CM, et al. Harsh corporal punishment is associated with increased $\mathrm{T} 2$ relaxation time in dopamine-rich regions. Neuroimage 2010;53:412-9.

38. Anda RF, Felitti VJ, Walker J, et al. The enduring effects of abuse and related adverse experiences in childhood: a convergence of evidence from neurobiology and epidemiology. Eur Arch Psychiatry Clin Neurosci 2006;256:174-86.

39. Trocmé N, MacLaurin B, Fallon B, et al. Canadian Incidence Study of Reported Child Abuse and Neglect: final report. Ottawa (ON): Public Health Agency of Canada; 2001.

40. Trocmé N, Fallon B, MacLaurin B, et al. Canadian Incidence Study of Reported Child Abuse and Neglect-2003: major findings. Ottawa (ON): Public Health Agency of Canada; 2005.

41. Clément $\mathrm{ME}$, Bouchard $\mathrm{C}$, Jetté $\mathrm{M}$, et al. La violence familiale dans la vie des enfants du Québec. Québec (QC): Institut de la statistique Québec; 2000.

42. Crandall M, Chiu B, Sheehan K. Injury in the first year of life: risk factors and solutions for high-risk families. J Surg Res 2006; 133:7-10.

43. Dietrich D, Berkowitz L, Kadushin A, et al. Some factors influencing abusers' justification of their child abuse. Child Abuse Negl 1990;14:337-45

44. Korbin JE. Incarcerated mothers' perceptions and interpretations of their fatally maltreated children. Child Abuse Negl 1987;11: 397-407. 
45. Wolfe DA. Child abuse: implications for child development and psychopathology. Newbury Park (NJ): Sage; 1987.

46. Durrant J, Ensom R; the Coalition on Physical Punishment of Children and Youth (2004). Joint statement on physical punishment of children and youth. Ottawa (ON): The Coalition; 2004. Available: www.cheo.on.ca/en/physicalpunishment. (accessed 2012 Jan. 15)

47. Durrant JE, Smith AB. Global pathways to abolishing physical punishment: Realizing children's rights. New York (NY): Routledge; 2011.

48. Patterson GR. The aggressive child: victim and architect of a coercive system. In: Mash IJ, Hamerlyck A, Handy LC, editors. Behaviour modification and families. New York (NY): Bruner/Mazel. p. 267-316.

49. Dretzke J, Davenport C, Frew E, et al. The clinical effectiveness of different parenting programmes for children with conduct problems: a systematic review of randomised controlled trials. Child Adolesc Psychiatry Ment Health 2009;3:7.

50. McCart MR, Priester PE, Davies WH, et al. Differential effectiveness of behavioural parent-training and cognitive-behavioral therapy for antisocial youth: a meta-analysis. J Abnorm Child Psychol 2006;34:527-43.

51. Prinz RJ, Sanders MR, Shapiro CJ, et al. Population-based prevention of child maltreatment: the US Triple P System Population Trial. Prev Sci 2009;10:1-12.

52. Canadian Paediatric Society. Guiding your child with positive discipline. Ottawa (ON): The Society; 2012. Available: www .caringforkids.cps.ca/behaviourparenting/PositiveDiscipline.htm (accessed 2012 Jan. 16)

53. Committee on psychosocial aspects of child and family health
Guidance for effective discipline. Elk Grove Village (IL): American Acadamy of Pediatrics; 1998. p. 723-8. Available: http://aappolicy aappublications.org/cgi/content/full/pediatrics;101/4/723 (accessed 2012 Jan. 16).

54. Bussman K-D, Erthal C, Schroth A. Effects of banning corporal punishment in europe: a five-nation comparison. In: Durrant JE, Smith AB, editors. Global pathways to abolishing physical pun ishment: realizing children's rights. New York (NY): Routledge; 2011. p. 299-322.

55. Spanking hurts more than you think [campaign]. Toronto (ON): City of Toronto. Available: www.toronto.ca/health/children /discipline.htm (accessed 2012 Jan. 16).

56. What's wrong with spanking? Ottawa $(\mathrm{ON})$ : The Public Health Agency of Canada. Available: www.phac-aspc.gc.ca/hp-ps /dca-dea/publications/spanking-fessee/index-eng.php (accessed 2012 Jan. 16).

57. Durrant JE. Physical punishment, culture, and rights: current issues for professionals. J Dev Behav Pediatr 2008;29:55-66.

Affiliations: From the Department of Family Social Sciences (Durrant), University of Manitoba, Winnipeg, Man.; and Partnerships and Advocacy (Ensom), the Children's Hospital of Eastern Ontario, Ottawa, Ont.

Contributors: Joan Durrant was the primary author and drafted the manuscript and its subsequent revisions. The article was conceptualized and finalized by Joan Durrant and Ron Ensom. Both authors approved of the final version submitted for publication.

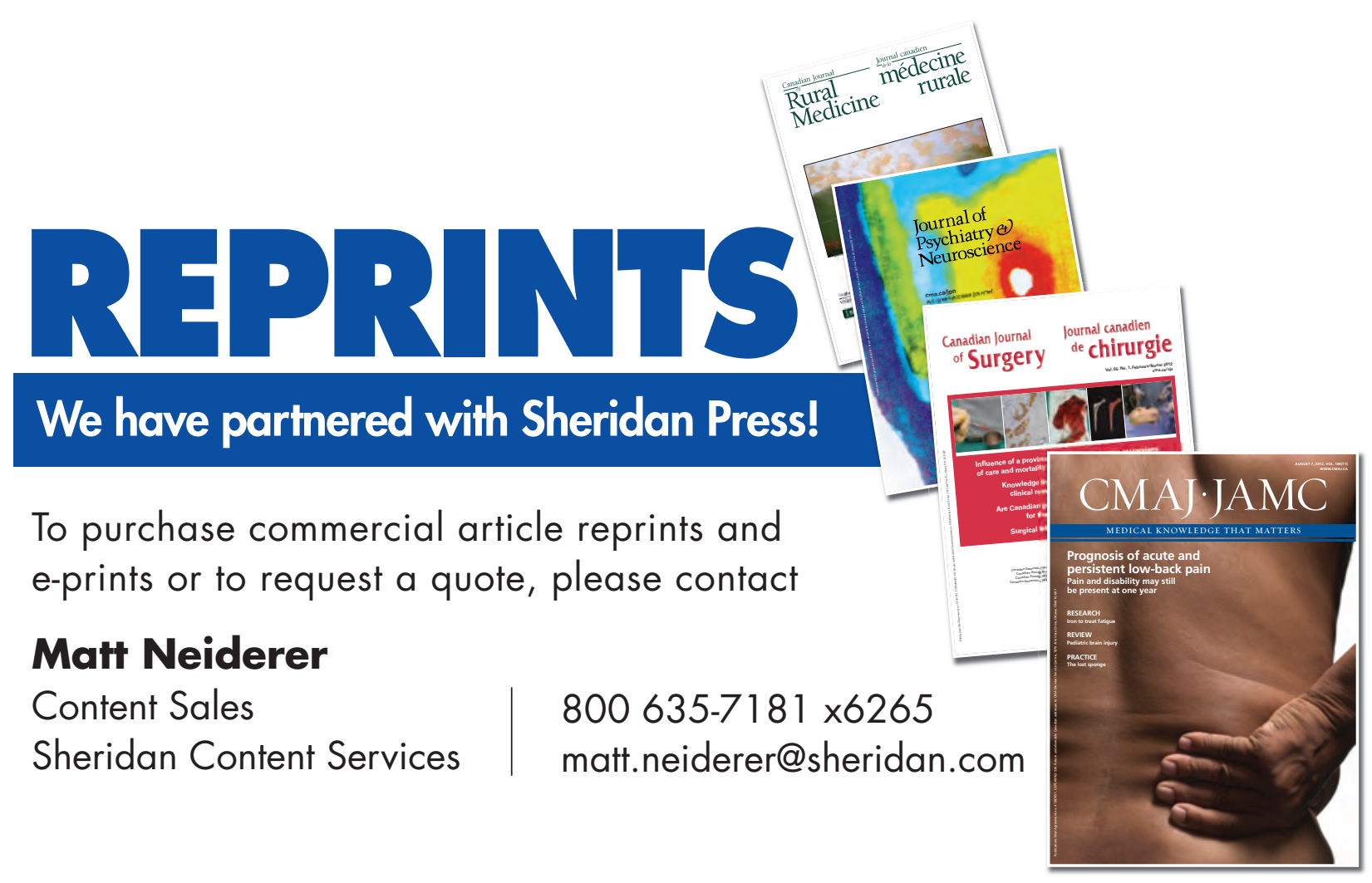

